\title{
Comparative Reliability of Screening Parameters for Anthracnose Resistance in Water Yam (Dioscorea alata)
}

Christian O. Nwadili, International Institute of Tropical Agriculture (IITA), Oyo Road, PMB 5320, Ibadan, Nigeria; and National Root Crops Research Institute, Umudike, Umuahia, Abia State, Nigeria; Joao Augusto, Ranjana Bhattacharjee, Joseph Atehnkeng, and Antonio Lopez-Montes, IITA, Ibadan, Nigeria; T. Joseph Onyeka, National Root Crops Research Institute, Abia State, Nigeria; and P. Lava Kumar, Robert Asiedu, and Ranajit Bandyopadhyay, IITA, Ibadan, Nigeria

\begin{abstract}
Anthracnose, caused by Colletotrichum gloeosporioides, is one of the major constraints limiting water yam (Dioscorea alata) production in the tropics. In this region, yam anthracnose control is mostly achieved by the deployment of moderately resistant yam genotypes. Therefore, screening for new sources of anthracnose resistance is an important aspect of yam research in the tropics. The reliability and applicability of different yam anthracnose rating parameters has not been fully examined. Disease severity on detached leaves in the laboratory and leaf severity, lesion size, and spore production on whole plants in the greenhouse were used to screen an F1 yam population and correlate screening results with field evaluations. Anthracnose lesion size had the smallest predicted

residual means but whole-plant severity and detached-leaf severity had the best variance homogeneity and relatively small predicted residual means. The concordance correlation coefficient $\left(r_{c}\right)$ and $\kappa$ statistic were used to determine the agreement between anthracnose rating parameters and field evaluations. Detached-leaf $\left(r_{c}=0.95, \kappa=0.81\right)$ and whole-plant $\left(r_{c}=0.96, \kappa=0.86\right)$ evaluations had high positive agreement with field evaluation but spore production $(\kappa=0.69)$ and lesion size $(\kappa=0.57)$ had moderate positive agreement. These results suggest that all the evaluated rating parameters can be used to successfully screen yam germplasm for anthracnose resistance but lesion size and spore production data may need to be transformed.
\end{abstract}

Anthracnose, caused by the fungal pathogen Colletotrichum gloeosporioides, is one of the major constraints limiting production wherever yam (Dioscorea spp.) is grown (Bayart and Pallas 1994; Onyeka et al. 2006b; Winch et al. 1984). The disease is particularly severe on Dioscorea alata, but other Dioscorea spp. can be affected as well (Akem and Asiedu 1994; Onyeka et al. 2006a). In Nigeria, yam anthracnose can cause tuber yield losses ranging from 50 to 90\% under favorable conditions for pathogen infection and disease development (Akem and Asiedu 1994). Infection and disease symptoms are concentrated on leaves but yam petioles, stems, and tubers are also infected. Typically, genetically diverse isolates of $C$. gloeosporioides can infect foliage and other plant tissues, including yam tubers at storage. Weir et al. (2012) have described more than 20 species, subspecies, and new taxa belonging to the $C$. gloeosporioides complex based on multigene phylogenies. The most virulent Nigerian isolates from yam foliage, characterized as slow-growing gray in potato dextrose agar (PDA) medium, matched a type specimen of a new species described as $C$. alatae (Weir et al. 2012). Yam isolates from Barbados, Guadeloupe, and India also belonged to the same clade, which does not contain isolates from other hosts (Weir et al. 2012). The characteristics of other yam isolates from Nigeria matched the characteristics of $C$. fructicola and $C$. siamense (Weir et al. 2012). We did not attempt to genetically distinguish the virulent yam isolates used in this study and, therefore, they will only be referred to as belonging to the $C$. gloeosporioides complex.

Control of yam anthracnose in Nigeria is hampered by limited availability of viable disease management options. Chemical application can be an effective disease control tool but it requires the correct selection of fungicides plus the appropriate application timing and rate. Most yam farmers are smallholder growers and may not have the

Corresponding author: J. Augusto; E-mail: J.Augusto@cgiar.org

*The $\boldsymbol{e}$-Xtra logo stands for "electronic extra" and indicates that one supplementary figure and one supplementary table are published online.

Accepted for publication 23 August 2016.

C 2017 The American Phytopathological Society required technical support and financial ability to afford the use of fungicides (Hepperly and Vazquez 1991). The occurrence of several virulent and genetically diverse isolates of the $C$. gloeosporioides complex infecting the same yam genotype or different genotypes within and between fields may lead to different sensitivity responses to fungicide applications. In addition, inappropriate use of fungicides could potentially lead to development of resistant strains of C. gloeosporioides to systemic fungicides (Bayart and Pallas 1994). Cultural practices, including the use of disease-free planting material, adjusting plant spacing and timing, incorporating infected plant residues in the soil immediately after harvesting, crop rotation with a nonhost crop, intercropping or crop mixture, and fallowing have been used in other plant pathosystems to decrease the pathogen inoculum in the field, delay disease onset, or slow disease progress (Reis et al. 1997; Simons and Green 1994). However, these disease management practices have not been shown to effectively control yam anthracnose or result in substantial tuber yield increase, especially in locations where the disease is endemic (Mignucci et al. 1988). Also, the use of nonplant-pathogenic microorganisms to inhibit or outcompete the multiplication and spread of virulent isolates of C. gloeosporioides complex in yam fields has been limited (Palaniyandi et al. 2011). Although a broad genetic base exists for breeding yam genotypes for anthracnose resistance in Nigeria, the effectiveness of the deployment of anthracnose-resistant genotypes partially depends on the availability of a reliable, innovative, and rapid screening method of yam germplasm for anthracnose reaction (Parlevliet 1993).

Comparative reliability and applicability of the anthracnose screening parameters in a controlled environment that favors pathogen infection, disease development, and plant growth, and for which results correlate with field yam germplasm reaction to anthracnose, have not been completely examined. Disease severity, lesion size, and spore production have been used as either rating parameters in disease resistance screenings or components of disease resistance for several crops and diseases (Gordon et al. 2006; Gumpert 1989; Metz et al. 2012; Onyeka et al. 2006b; Tredway et al. 2003). For yam anthracnose, disease severity is widely used as a standard parameter to screen yam genotypes for resistance either as a one-time disease rating (e.g., final disease severity) or cumulative disease ratings (e.g., area under the disease progress curve) (Aduramigba-Modupe et al. 2008; Nwankiti et al. 1987; Onyeka et al. 2006a,b; Sweetmore et al. 1994). Most of the 
anthracnose severity screenings in yam are carried out in the greenhouse using the whole-plant inoculation technique with one or several virulent strains of $C$. gloeosporioides, while laboratory inoculations using a detached-leaf technique are rarely employed. Lesion size has been shown to correlate with severity in other plant pathosystems (Nutter and Pederson 1985) but its efficacy in yam anthracnose has not been explored. Although the measurement of spore production or spore production rate is relatively tedious and time consuming, it can provide an accurate estimation of pathogen ability to grow on a susceptible host. The concordance correlation coefficient $\left(r_{c}\right)$ and Cohen's $\kappa$ statistic are appropriate to measure the agreement between two or more continuous and categorical disease rating parameters, respectively (Cohen 1960; Lin 1989; Nickerson 1997). The к statistic can also be used to compare the ability of the different disease rating parameters to classify the yam genotypes into several groups of anthracnose resistance (Cohen 1960). The reproducibility and reliability of anthracnose leaf severity, spore production, and lesion size as rating parameters for yam anthracnose resistance in greenhouse and laboratory tests needed to be determined. The objectives of this study were to (i) determine the relative effectiveness of different yam anthracnose resistance screening parameters in laboratory and greenhouse conditions and (ii) corroborate laboratory and greenhouse yam anthracnose screening results with field anthracnose resistance evaluations.

\section{Materials and Methods}

Forty-one isolates of $C$. gloeosporioides, originally collected from naturally infected yam leaves in 2008 in five West African countries (Nigeria, Ghana, Ivory Coast, Togo, and Benin) representing different agroecological zones, were evaluated for virulence in the laboratory and greenhouse at International Institute of Tropical Agriculture (IITA; $07^{\circ} 30^{\prime} 01.7^{\prime \prime} \mathrm{N}, 003^{\circ} 54^{\prime} 29.4^{\prime \prime} \mathrm{E}$ ) in Ibadan, Nigeria, in 2011 using four D. alata accessions (TDa 00/00005, TDa 99/240, TDa 00/00194, and TDa 93-36) carrying different genes for resistance to C. gloeosporioides (Abang et al. 2001; Mignouna et al. 2001). Four C. gloeosporioides isolates-Kog01R1, Del06R2 (Nigeria), Tog12A1 (Togo), and Gha09A1 (Ghana)—were the most virulent

Table 1. Analysis of nonparametric response variable (anthracnose severity rating) in the F1 yam population at IITA, Ibadan, Nigeria, 2011 to 2013

\begin{tabular}{|c|c|c|c|c|c|}
\hline \multirow[b]{2}{*}{ Parameter $^{b}$} & \multicolumn{5}{|c|}{ Yam anthracnose severity (1-to-5 scale) ${ }^{a}$} \\
\hline & Estimate & $\mathbf{S E}^{\mathrm{c}}$ & Wald $\chi^{2}$ & $\operatorname{Pr}>\chi$ & $95 \% C^{d}$ \\
\hline Intercept 1 & 0.5087 & 0.0947 & 2.1312 & 0.3487 & -0.41180 .8970 \\
\hline Intercept 2 & -0.1149 & 0.2364 & 1.0843 & 0.2167 & -0.26772 .1666 \\
\hline Intercept 3 & -0.0983 & 0.1925 & 2.0084 & 0.1028 & -0.20022 .6687 \\
\hline Intercept 4 & -1.2108 & 0.2121 & 1.1297 & 0.3124 & -2.87423 .5810 \\
\hline Year & -0.1287 & 0.2018 & 1.5784 & 0.7701 & -0.38870 .2318 \\
\hline $\begin{array}{l}\text { F1 yam population } \\
\text { laboratory }\end{array}$ & 3.0124 & 0.1214 & 12.1081 & 0.0001 & 0.50015 .2974 \\
\hline Greenhouse & 3.2631 & 0.2200 & 15.9901 & 0.0001 & 0.87126 .6784 \\
\hline Field & 3.4704 & 0.4914 & 8.3308 & 0.0123 & 0.11877 .8416 \\
\hline Scale $^{\mathrm{e}}$ & 1.0000 & 0.0000 & $\ldots$ & $\ldots$ & 1.00001 .0000 \\
\hline
\end{tabular}

a Analysis of maximum likelihood parameter estimates of categorical or ordinal data with PROC GENMOD. An F1 yam population was assessed for anthracnose severity in the laboratory, 1 week after inoculation, using a 1-to-5 rating scale, where $1=0$ to $5,2=>5$ to $10,3=>10$ to $25,4=>25$ to 50 , and $5=>50 \%$ of leaf area affected. Likewise, the F1 yam population was assessed for anthracnose severity in the greenhouse, 1 week after inoculation, and in the field, 3 months after inoculation, using a 1-to-5 rating scale, where $1=0$ to $5,2=>5$ to $10,3=>10$ to $25,4=>25$ to 50 , and $5=>50 \%$ of plant area affected. Data on anthracnose severity were subjected to statistical analysis using Proc GENMOD of the SAS software (version 9.4) for categorical or ordinal variables.

b Intercept terms (1, 2, 3, and 4) depended only on response (anthracnose severity) categories $(\kappa)$ and were modeled by the cumulative logit link function of the multinomial distribution for $\kappa-1$.

c Standard error.

${ }^{\mathrm{d}}$ Wald $95 \%$ confidence limits

e The scale parameter was held fixed. (results not shown) and were selected for use in the subsequent studies.

Laboratory assessment of an F1 yam mapping population for anthracnose resistance. Young, fully expanded leaves of 2-monthold plants were obtained from 98 water yam $(D$. alata) genotypes consisting of $96 \mathrm{~F} 1$ progenies and their two parents (a resistant female and a susceptible male), grown in the greenhouse at IITA in Ibadan, Nigeria. Detached leaves were inoculated with virulent strains of C. gloeosporioides in the laboratory in 2012 and 2013 following the method of Green et al. (2000) to assess genotypes' resistance to yam anthracnose. Briefly, the isolates were grown on PDA amended with lactic acid. The isolates were incubated at $26^{\circ} \mathrm{C}$ under a cycle of $12 \mathrm{~h}$ of fluorescent light $\left(60 \mathrm{lE} / \mathrm{m}^{2} / \mathrm{s}\right)$ and $12 \mathrm{~h}$ of darkness to induce sporulation. Eight-day-old plate cultures were flooded with sterile distilled water supplemented with the wetting agent Tween $20(0.05 \%$ [vol/vol]) and spores were gently scraped off the plates using sterilized plastic spreader. The density of spore suspensions was measured using a hemocytometer, and suspension concentrations were adjusted to $1 \times$ $10^{6}$ spores $/ \mathrm{ml}$ of water. Leaves were inoculated with a conidial suspension at $1 \times 10^{6}$ spores $/ \mathrm{ml}$ of water consisting of the four most virulent C. gloeosporioides isolates (Kog01R1, Del06R2, Tog12A1, and Gha09A1).

The detached leaves were first surface disinfected by immersion in a $1.0 \%(\mathrm{vol} / \mathrm{vol})$ solution of commercial sodium hypochlorite for $2 \mathrm{~min}$, followed by three 1-min rinses in sterile distilled water. The leaves were placed on sterile paper towels inside a sterile plastic container in a laminar flow cabinet in order to remove excess moisture prior to inoculation. Four detached leaves per genotype were point inoculated with conidial suspension at the middle of the adaxial surfaces using a pipette set at $30 \mu \mathrm{l}$. Detached leaves receiving sterile distilled water amended with Tween 20 served as a control. The inoculated leaves were incubated at $26^{\circ} \mathrm{C}$ at $100 \%$ relative humidity under a cycle of $12 \mathrm{~h}$ of fluorescent light $\left(60 \mathrm{lE} / \mathrm{m}^{2} / \mathrm{s}\right)$ and $12 \mathrm{~h}$ of darkness. The experimental design layout was a randomized complete block and treatments (yam genotypes) were replicated four times.

The leaves were visually scored 7 days after inoculation for anthracnose severity, based on proportion of affected leaf area at the point of inoculation, using a 1-to-5 rating scale, where $1=0$ to $5,2=>5$ to $10,3=>10$ to $25,4=>25$ to 50 , and $5=>50 \%$ of leaf area affected. Similarly, yam genotypes with anthracnose severity scores of 1, 2, 3, 4, and 5 were characterized as highly resistant, resistant, moderately resistant, susceptible, and highly susceptible, respectively.

Greenhouse assessment of the F1 yam mapping population for anthracnose resistance. The $98 \mathrm{D}$. alata genotypes were screened for anthracnose resistance in 2011, 2012, and 2013 using whole plants derived from a nodal cutting method (Ryo et al. 2010) of plantlets from minisetts raised in large plastic pots $(18 \mathrm{~cm}$ in diameter by $25 \mathrm{~cm}$ in height). The experiment was in a balanced randomized complete block design and treatments (genotypes) were replicated four times. The yam plantlets were grown in a pasteurized topsoil mixed with rice husk and coarse soil in a ratio of 3:2:1, under 13-h photoperiods at $26 \pm 2{ }^{\circ} \mathrm{C}$ (Ryo et al. 2010). The plantlets were prepared by using the vine-cutting technique (Acha et al. 2004; Agele et al. 2010; Kikuno et al. 2007). The pots were filled with $3 \mathrm{~kg}$ of soilrice husk mixture, flooded with water, and allowed to settle before the vine cuttings were planted. Vine cuttings were grown for 8 weeks until the plantlets had developed four or more leaves, then inoculated. Prior to inoculation, the humidity in the greenhouse was increased to $>90 \%$ by using a humidifier for 2 days. Plants were inoculated to near runoff with a spore suspension $\left(1 \times 10^{6}\right.$ conidia/ml of water $)$ consisting of the four isolates of $C$. gloeosporioides previously described. The spores were harvested from 8-day-old cultures grown on PDA. Inoculated yam genotypes were immediately enclosed in plastic bags to maintain relative humidity at $>90 \%$ and maintained at $26 \pm 2{ }^{\circ} \mathrm{C}$.

Anthracnose severity rating. All plants for each yam genotype in the four replications were visually evaluated for anthracnose severity 7 days after inoculation using a 1 -to-5 rating scale, where $1=0$ to 5 , 
$2=>5$ to $10,3=>10$ to $25,4=>25$ to 50 , and $5=>50 \%$ of plant area affected. The yam genotypes were rated for anthracnose severity during 2011, 2012, and 2013.

Anthracnose lesion size rating. Prior to inoculation, one leaf in the top, middle, and bottom canopies for each of the 2-month-old yam plants was arbitrarily selected and tagged for subsequent ratings of anthracnose lesion size 7 days after inoculation. Three arbitrarily selected lesions at each top (Top), middle (Mid), and bottom (Bot) canopy were used to calculate the mean of lesion length (LL) and width (LW) for each yam genotype. The lesion size was an arithmetic mean

Table 2. Analysis of parametric response variables (anthracnose lesion size and spore production) in the $\mathrm{F} 1$ yam population

\begin{tabular}{lrrrrrrrr}
\hline & \multicolumn{3}{c}{ Type 3 tests of fixed effects of numerical data with } \\
PROC MIXED
\end{tabular}
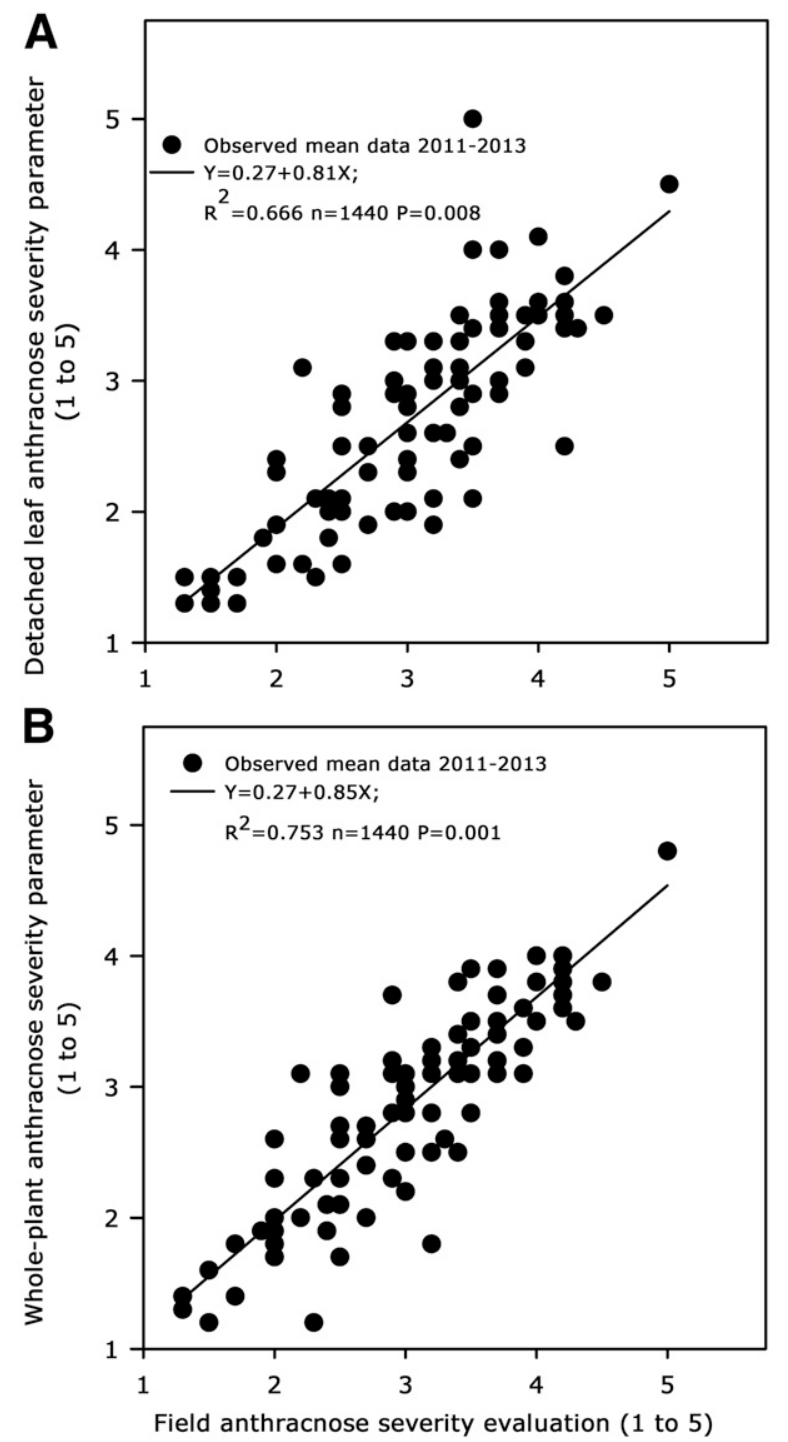

of length and width measurements conducted on leaves collected from the top, middle, and bottom canopies and was calculated as follows: lesion size $=[($ LLTop + LWTop $) / 2+($ LLMid + LWMid $) / 2$ $($ LLBot + LWBot $) / 2] / 3$.

Spore production rating. Twelve leaves for each genotype, detached from top, middle, and bottom canopies and from arbitrarily selected plants in each replication, were collected and transported to the laboratory in sterile nylon bags 7 days after inoculation. Lesions were excised with a cork borer for quantification of sporulation as conidia per lesion area using a modified method of Alderman and Beute (1987). Conidia were dislodged by placing three lesion disks from top, middle, and bottom canopies for each yam genotype from each replication in a vial containing $2 \mathrm{ml}$ of water amended with $0.05 \mathrm{ml}$ of Tween 20 per $100 \mathrm{ml}$ of water and stirring them with a microstirbar for $1 \mathrm{~min}$. Numbers of conidia per 100 milliliter of water were based on average hemocytometer counts from the four replications (each with three canopies). Lesion area was predetermined based on the diameter of the cork borer.

Field evaluation of the F1 yam mapping population for anthracnose resistance. The 98 yam genotypes were also evaluated for anthracnose resistance in 2012 and 2013 at the IITA Ibadan farm research field $\left(07^{\circ} 30^{\prime} 20.7^{\prime \prime} \mathrm{N}\right.$; $\left.003^{\circ} 54^{\prime} 08.4^{\prime \prime} \mathrm{E}\right)$. The field was bottom plowed to a depth of 20 to $25 \mathrm{~cm}$, disk harrowed, and marked off in plots of 2 by $5 \mathrm{~m}$ before planting. Preemergence herbicides ethalfluralin $(0.72 \mathrm{~kg}$
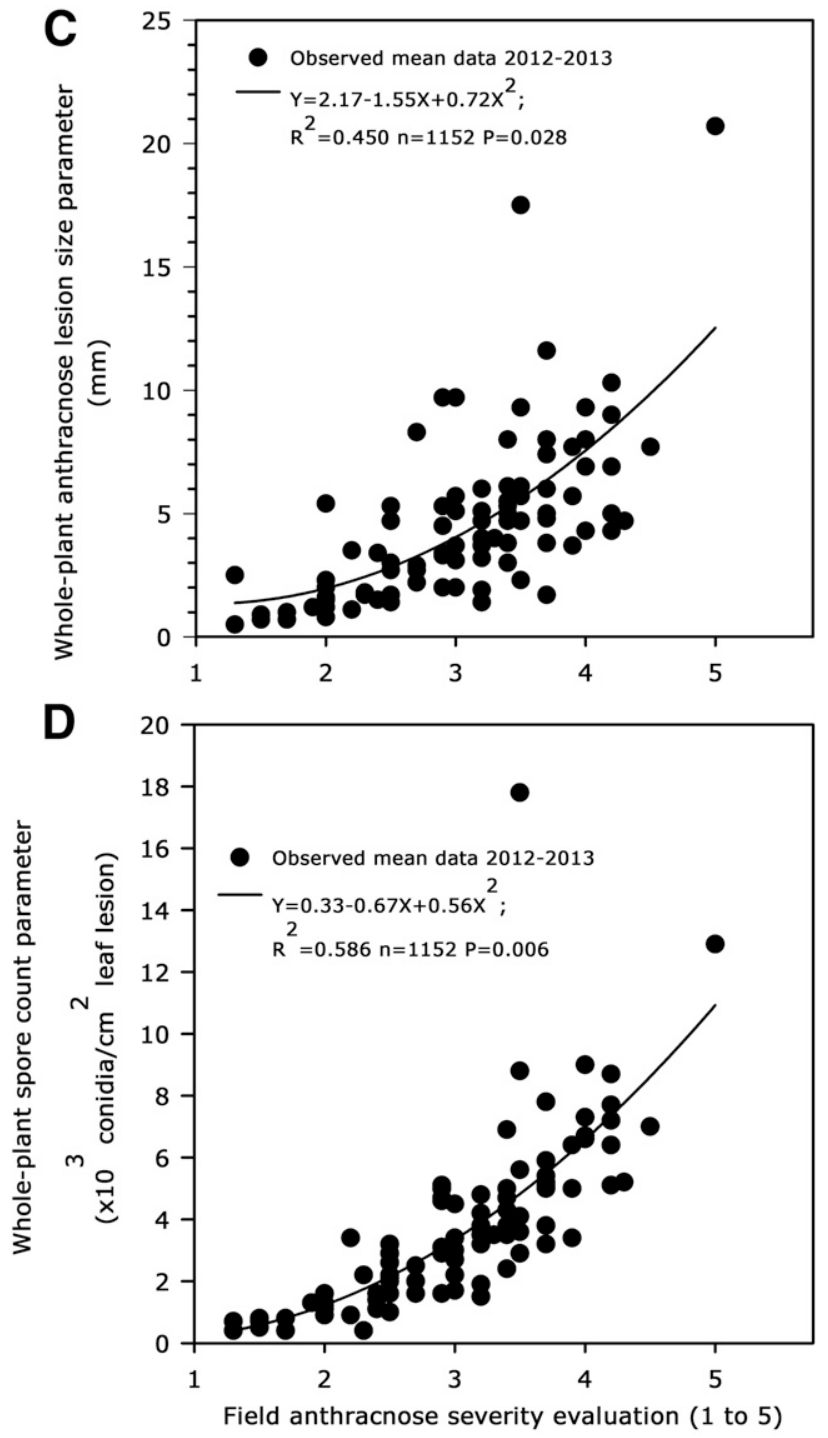

Fig. 1. Relationship between field anthracnose severity and A, detached-leaf anthracnose severity conducted in the laboratory; $\mathbf{B}$, whole-plant anthracnose severity in greenhouse; $\mathbf{C}$, anthracnose lesion size in greenhouse; and $\mathbf{D}$, Colletotrichum gloeosporioides spore production in greenhouse for the F1 yam population. 
a.i./ha, Sonalan; Dow AgroSciences, Indianapolis, IN) and S-metolachlor (1.5 kg a.i./ha, Dual Magnum; Syngenta Crop Protection, Inc., Greensboro, NC) were applied on soil a week before planting. The experiment was a balanced randomized complete block design and treatments (yam genotypes) were replicated four times. The treatments consisted of $96 \mathrm{~F} 1$ yam progenies and their respective susceptible male and resistant female parents that were used as the controls for evaluating anthracnose resistance. The planting dates were 7 July 2012 and 14 July 2013 and all plots consisted of two 5-m-long rows. Genotypes were manually planted between and within the rows' spacing of $1 \mathrm{~m}$. A spore suspension consisting of the four virulent isolates previously described at a concentration of $1 \times 10^{6}$ conidia/ml of water was uniformly applied to yam foliage to runoff at 10 liters/ha 1 month after planting. Plots were maintained using common management practices, including hand weeding and irrigation, when needed, but no fungicides were applied.

Anthracnose severity rating and yield assessment. The 4-monthold plants were visually assessed for anthracnose severity 3 months after inoculation and 2 weeks before harvesting the tubers, using the 1-to-5 severity rating scale as previously described. Anthracnose severity assessments were taken in all four replications in each genotype for the 2012 and 2013 crop seasons. At harvesting, yam tubers were weighed and yield was determined for each genotype.

Statistical analysis of the laboratory, greenhouse, and field experiments. Anthracnose severity data for the laboratory, greenhouse, and field experiments were subjected to categorical modeling using the PROC GENMOD of SAS software (version 9.4; SAS Institute, Cary, NC) fitting categorical or ordinal variables. Genotypes of the $\mathrm{F} 1$ yam population were modeled as the explanatory variables and the yam anthracnose severity as the response variable. The "multinomial" probability distribution and the "cumulative logit" built-in link function were invoked to model yam anthracnose severity variable with five response categories $(1=0$ to $5,2=>5$ to $10,3=>10$ to $25,4=>25$ to 50 , and $5=>50 \%$ of leaf or plant area affected). This was considered as an ordinal model because the multinomial categories are in a natural order. The model was constructed by first fitting an intercept as the only explanatory variable and, then, sequentially adding each F1 yam population for the laboratory, greenhouse, and field tests in the successive models. The contribution

Table 3. Concordance correlation coefficients $\left(r_{c}\right)$ and weighted Cohen's $\kappa$ statistics for agreements between laboratory, greenhouse rating parameters, and field anthracnose evaluation of an F1 yam population in 2011 to 2013

\begin{tabular}{|c|c|c|c|}
\hline \multicolumn{2}{|c|}{ Anthracnose rating parameter } & \multirow[b]{2}{*}{$r_{c}(\mathrm{CI})^{\mathrm{c}}$} & \multirow[b]{2}{*}{$\begin{array}{l}\text { Weighted } \\
\kappa(\mathbf{C I})^{\mathbf{d}}\end{array}$} \\
\hline $\begin{array}{l}\text { Laboratory, } \\
\text { greenhouse }^{\mathbf{a}}\end{array}$ & Field $^{\mathrm{b}}$ & & \\
\hline \multicolumn{4}{|l|}{ Laboratory } \\
\hline $\begin{array}{l}\text { Detached-leaf } \\
\text { severity }\end{array}$ & $\begin{array}{l}\text { Field severity } \\
\text { evaluation }\end{array}$ & $0.95(0.92,0.98)$ & $0.81(0.79,0.86)$ \\
\hline \multicolumn{4}{|l|}{ Greenhouse } \\
\hline $\begin{array}{l}\text { Whole-plant } \\
\text { severity }\end{array}$ & $\begin{array}{l}\text { Field severity } \\
\text { evaluation }\end{array}$ & $0.96(0.93,0.99)$ & $0.86(0.83,0.88)$ \\
\hline Lesion size & $\begin{array}{l}\text { Field severity } \\
\text { evaluation }\end{array}$ & $\ldots$ & $0.57(0.51,0.60)$ \\
\hline Spore production & $\begin{array}{l}\text { Field severity } \\
\text { evaluation }\end{array}$ & $\ldots$ & $0.69(0.66,0.73)$ \\
\hline \multicolumn{4}{|c|}{$\begin{array}{l}\text { a Laboratory and greenhouse ratings of anthracnose in the F1 yam population } \\
\text { were taken from } 2011 \text { to } 2013 \text { at IITA headquarters in Ibadan, Nigeria. }\end{array}$} \\
\hline \multicolumn{4}{|c|}{$\begin{array}{l}{ }^{\mathrm{b}} \text { Field evaluation of anthracnose in the F1 yam population was conducted } \\
\text { from } 2012 \text { to } 2013 \text { at IITA Ibadan experimental fields. }\end{array}$} \\
\hline \multicolumn{4}{|c|}{$\begin{array}{l}{ }^{\mathrm{c}} \text { The } r_{c} \text { were determined for agreements between anthracnose severity rating } \\
\text { parameters in the laboratory, greenhouse, and field. Numbers in parentheses } \\
\text { are } 95 \% \text { confidence intervals (CI). Only severity rating parameters in the lab- } \\
\text { oratory and greenhouse were compared with field anthracnose severity } \\
\text { evaluation. }\end{array}$} \\
\hline \multicolumn{4}{|c|}{$\begin{array}{l}\mathrm{d} \text { The } \mathrm{F} 1 \text { yam population was grouped into five categories of resistance to an- } \\
\text { thracnose based on each disease rating parameter and field evaluation re- } \\
\text { sults, where } 1=\text { highly resistant, } 2=\text { resistant, } 3=\text { moderately resistant, } 4= \\
\text { susceptible, and } 5=\text { highly susceptible. Weighted Cohen's } \kappa \text { were then deter- } \\
\text { mined for agreements between the anthracnose rating parameters and field } \\
\text { evaluation. Numbers in parentheses are asymptotic } 95 \% \mathrm{CI} \text {. }\end{array}$} \\
\hline
\end{tabular}

of each F1 yam population (i.e., in the laboratory, greenhouse, and field) to the model was determined by changes of deviance in the "goodness-of-fit statist" output. Type 1 and type 3 analyzes were invoked to generate the statistical significances of each F1 yam population term to the model. The "Analysis of the Parameter Estimates" output was generated to summarize the estimate, standard error, Wald $95 \%$ confidence limits, Wald $\chi^{2}$, and probabilities for each parameter. Proc Corr and Var Model (for Proc Print) statements were invoked to calculate $r_{c}$ and $95 \%$ confidence limits, respectively, to assess the agreement between anthracnose rating parameters detached-leaf severity (in the laboratory), whole-plant severity (in the greenhouse), and field anthracnose severity evaluation. Yam genotypes were also grouped into the five categories of anthracnose reaction based on the anthracnose severity from the three different tests. The AGREE option in Proc FREQ was also invoked to calculate the unweighted $\kappa$ statistic for the categorical data to assess the agreement between each of the anthracnose rating parameters and field anthracnose evaluation. Lesion size, spore production, and tuber yield were subjected to analysis of variance using the mixed procedure of SAS to determine significant differences among yam genotypes. Data on lesion size and spore production were subjected to square-root transformation before statistical analysis to normalize the variance. Statistical analysis for anthracnose severity, lesion size, spore production, and tuber yield was performed with data arranged in a randomized complete block design but data from greenhouse, laboratory, and field were nested within years. All means for lesion size, spore production, and tuber yield were separated by Fisher's protected least significant difference $(P=0.05)$.

\section{Results}

The generated "Criteria for Assessing Goodness of Fit" output (not shown) for the anthracnose severity categorical and ordinal data modeling had deviances numerically close to the respective parameters' degree of freedom and greater than 1, both indicative of good fit of the models. The "Analysis of Maximum Likelihood Parameter Estimates" output showed that the year effect had no influence on anthracnose severity of the yam genotypes $(P=0.7701)$. Year and all four intercepts had zero included within their respective Wald $95 \%$ confidence limits, further indicating the parameters' insignificance to the models. The response of the F1 yam population to anthracnose severity was significant in the laboratory $(P=0.0001)$, greenhouse $(P=0.0001)$, and field $(P=0.0123)$ testing. All laboratory, greenhouse, and field parameters had Wald $95 \%$ confidence limits higher than zero, further suggesting the significance of the parameters to the models (Table 1).

The analysis of variance "Type 3 Tests of Fixed Effects" output showed no significant interaction year-F1 yam population for both anthracnose lesion size and spore production. Only the partial effect F1 yam population was significant for both anthracnose lesion size $(P=0.0078)$ and spore production $(P=0.0028)$ (Table 2$)$.

The output of marginal residual plots showed that total variances of spore production and lesion were not homogeneous and data were square-root transformed before statistical analysis. Lesion size followed by detached-leaf severity and whole-plant severity had the least predicted residual means while the spore production rating parameter had the highest (Supplementary Fig. S1).

Laboratory assessment of the F1 yam mapping population for anthracnose resistance. The relationship between the detachedleaf anthracnose severity and field anthracnose severity was best fit $\left(R^{2}=0.666, P=0.008\right)$ with a linear regression model (Fig. 1A).

The $r_{c}\left(r_{c}=0.95\right)$ and weighted Cohen's $\kappa$ statistic $(\kappa=0.81)$ showed high positive agreement between the detached-leaf anthracnose severity and field anthracnose severity. The confidence intervals at $95 \%$ were $0.92,0.98$ for $r_{c}$, and $0.79,0.86$, for $\kappa$ (Table 3 ).

The anthracnose-susceptible male parent had high severity and was classified as susceptible while the anthracnose-resistant female parent was rated as moderately resistant using the detached-leaf anthracnose severity rating parameter (Table 4; Supplementary Table $\mathrm{S} 1)$. The phenotyping of the 96 individuals in the $\mathrm{F} 1$ yam population with the detached-leaf anthracnose severity rating parameter resulted in $4.1 \%$ of the genotypes classified as highly resistant, $34.4 \%$ as 
resistant, $44.8 \%$ as moderately resistant, $14.6 \%$ as susceptible, and $2.1 \%$ as highly susceptible (Fig. 2A).

About $83 \%(n=80)$ and $39 \%(n=37)$ of the F1 yam progenies had anthracnose severity ratings lower than their susceptible male and resistant female parents, respectively, when the detached-leaf severity was used. About $46 \%(n=44)$ of the F1 yam progenies had anthracnose severity ratings similar to their resistant female parent (Table 4).

Greenhouse assessment of the F1 yam mapping population for anthracnose resistance. The disease pressure from the artificial inoculation was high and the anthracnose-susceptible male yam parent had a severity rating of 5.0, and was classified as highly susceptible. The anthracnose-resistant female parent had severity rating of 3.0 and was classified as moderately resistant. Similarly, the susceptible male parent had larger lesions, as a result of enlargement or coalescence of the individual lesions, and had a higher number of conidia produced by the leaf lesion surface area than the resistant female parent. No yam progeny was immune to anthracnose (Table 4).

The relationship between the whole-plant anthracnose severity and field anthracnose severity was best fit $\left(R^{2}=0.753, P=0.001\right)$ by a linear regression model (Fig. 1B) but the relationships between lesion size $\left(R^{2}=0.450, P=0.028\right)$, spore production $\left(R^{2}=0.586, P=\right.$ 0.006 ), and field anthracnose severity were best explained by quadratic models (Fig. 1C and D, respectively).

The $r_{c}\left(r_{c}=0.96\right)$ and weighted Cohen's $\kappa$ statistic $(\kappa=0.86)$ showed the highest positive agreement between the whole-plant anthracnose severity and field anthracnose severity. The confidence intervals at $95 \%$ were $0.93,0.99$ for $r_{c}$, and $0.83,0.88$ for $\kappa$ (Table 3). For yam anthracnose lesion size and $C$. gloeosporioides spore production, only categorical data for reaction of the $\mathrm{F} 1$ yam population to anthracnose $(1$ = highly resistant, 2 = resistant, $3=$ moderately resistant, $4=$ susceptible, and $5=$ highly susceptible) were used to establish the agreement between the screening parameters and field anthracnose evaluation. Lesion size $(\kappa=0.57)$ and spore production $(\kappa=0.69)$ had moderate positive agreement with field severity. The confidence intervals at $95 \%$ were $0.51,0.60$ and $0.66,0.73$, respectively (Table 3 ).

The phenotyping of the $96 \mathrm{~F} 1$ yam population using the wholeplant anthracnose severity resulted in $5.2 \%$ of the yam progenies classified as highly resistant, $25.0 \%$ as resistant, $44.8 \%$ as moderately resistant, $24.0 \%$ as susceptible, and $1.0 \%$ as highly susceptible (Fig. 2B). With anthracnose lesion size as the rating parameter, $7.3 \%$ of the yam progenies were classified as highly resistant, $17.7 \%$ as resistant, $40.6 \%$ as moderately resistant, $30.2 \%$ as susceptible, and $4.2 \%$ as highly susceptible (Fig. 2, C). Similarly, $11.5 \%$ of the genotypes were rated as highly resistant, $20.8 \%$ as resistant, $43.7 \%$ as moderately resistant, $21.9 \%$ as susceptible and $2.1 \%$ as highly susceptible when using spore production as the rating parameter (Fig. 2, D).

About $99 \%(n=95)$ and $30 \%(n=29)$ of the $\mathrm{F} 1$ yam progenies had whole-plant anthracnose severity lower than their susceptible and

Table 4. Laboratory, greenhouse, and field evaluations of anthracnose resistance of the F1 yam population in 2011 to $2013^{\mathrm{a}}$

\begin{tabular}{|c|c|c|c|c|c|c|}
\hline \multirow[b]{3}{*}{ F1 yam population ${ }^{b}$} & \multicolumn{4}{|c|}{ Laboratory and greenhouse anthracnose screening } & & \\
\hline & \multirow{2}{*}{$\begin{array}{c}\text { Detached leaf } \\
\text { Sev } \\
(1 \text { to } 5)^{\mathrm{c}}\end{array}$} & \multicolumn{3}{|c|}{ Whole plant } & \multicolumn{2}{|c|}{ Field evaluation } \\
\hline & & $\begin{array}{c}\text { Sev } \\
(1 \text { to } 5)^{d}\end{array}$ & $\begin{array}{c}\text { Lesion } \\
(\mathrm{mm})^{\mathrm{e}}\end{array}$ & $\begin{array}{c}\text { Spore production } \\
\left(\times 10^{3} \text { conidia/ } \mathrm{cm}^{2} \text { leaf lesion }\right)^{\mathrm{f}}\end{array}$ & $\begin{array}{l}\text { Anthracnose } \\
(1 \text { to 5) }\end{array}$ & $\begin{array}{c}\text { Tuber yield } \\
\text { (kg/ha) }\end{array}$ \\
\hline TDa 95-310 (S male $)^{\mathrm{h}}$ & 4.0 & 5.0 & 10.3 & 11.0 & 4.0 & $1,667.0$ \\
\hline TDa 95/00328 (R female $)^{\mathrm{i}}$ & 3.0 & 3.0 & 3.7 & 3.6 & 3.0 & $14,333.0$ \\
\hline TDa 10/00961 & 2.0 & 1.0 & 2.5 & 0.7 & 1.0 & $27,333.0$ \\
\hline TDa 10/00996 & 1.0 & 1.0 & 0.5 & 0.4 & 1.0 & $36,667.0$ \\
\hline TDa 10/00982 & 1.0 & 1.0 & 0.9 & 0.7 & 2.0 & $52,667.0$ \\
\hline TDa 10/00914 & 1.0 & 2.0 & 0.7 & 0.8 & 2.0 & $22,000.0$ \\
\hline TDa 10/00927 & 2.0 & 2.0 & 0.7 & 0.5 & 2.0 & $16,667.0$ \\
\hline TDa 10/01073 & 1.0 & 1.0 & 0.7 & 0.8 & 2.0 & $34,667.0$ \\
\hline TDa 10/00964 & 2.0 & 2.0 & 1.0 & 0.4 & 2.0 & $27,667.0$ \\
\hline TDa $10 / 01005$ & 2.0 & 2.0 & 1.2 & 1.3 & 2.0 & $25,667.0$ \\
\hline TDa 10/01140 & 2.0 & 2.0 & 0.8 & 0.9 & 2.0 & $23,000.0$ \\
\hline TDa 10/00913 & 2.0 & 2.0 & 1.2 & 1.2 & 2.0 & $21,000.0$ \\
\hline TDa $10 / 01177$ & 2.0 & 2.0 & 5.4 & 1.1 & 2.0 & $27,333.0$ \\
\hline TDa $10 / 01050$ & 2.0 & 2.0 & 1.5 & 1.3 & 2.0 & $30,000.0$ \\
\hline TDa 10/01039 & 2.0 & 2.0 & 1.6 & 1.3 & 2.0 & $21,333.0$ \\
\hline TDa 10/00948 & 2.0 & 2.0 & 2.0 & 1.6 & 2.0 & $14,667.0$ \\
\hline TDa 10/01069 & 2.0 & 3.0 & 2.3 & 1.3 & 2.0 & $19,333.0$ \\
\hline TDa 10/01053 & 3.0 & 3.0 & 3.5 & 3.4 & 2.0 & $21,667.0$ \\
\hline \multirow[t]{2}{*}{ TDa 10/01165 } & 2.0 & 2.0 & 1.1 & 0.9 & 2.0 & $22,000.0$ \\
\hline & & & & & \multicolumn{2}{|c|}{ (continued on next page) } \\
\hline
\end{tabular}

${ }^{a}$ Two-month-old yam plants were inoculated with a mixture of conidial suspension $\left(1 \times 10^{6}\right.$ spores $\left./ \mathrm{ml}\right)$ of Colletotrichum gloeosporioides isolates Kog01R1, Del06R2, Tog12A1, and Gha09A1 in the greenhouse and field. Leaves were sprayed with conidial suspension until run-off. Leaves across bottom, middle, and top yam canopies were arbitrarily tagged before inoculation for severity, lesion size, and spore production assessments.

${ }^{b}$ Only results of 50 (of 96) F1 yam population are shown. The F1 yam population (from crosses of one anthracnose-susceptible male and one anthracnoseresistant female parent) was screened and evaluated for anthracnose reactions in the laboratory, greenhouse, and field from 2011 to 2013 . LSD $=$ least significant difference.

${ }^{\mathrm{c}}$ Detached leaves were visually assessed for anthracnose severity (Sev) 7 days after inoculation using a 1 -to-5 rating scale, where $1=0$ to $5,2=>5$ to $10,3=>10$ to $25,4=>25$ to 50 , and $5=>50 \%$ of leaf area affected.

${ }^{\mathrm{d}}$ Yam genotypes in the greenhouse were visually assessed for anthracnose severity (Sev) 7 days after inoculation using a 1-to-5 rating scale, where $1=0$ to 5 , $2=>5$ to $10,3=>10$ to $25,4=>25$ to 50 , and $5=>50 \%$ of plant area affected.

${ }^{\mathrm{e}}$ Lesion sizes were recorded 7 days after inoculation as an arithmetic mean of two cross measurements.

${ }^{\mathrm{f}}$ Lesions were excised 7 days after inoculation with a cork borer for quantification of sporulation as conidia/lesion area. Numbers of conidia were based on average hemocytometer counts. Lesion area was determined using a formula for area of a circle for the lesion disks.

$\mathrm{g}$ Yam genotypes in the field were visually assessed for anthracnose resistance 4 months after planting and 2 weeks before tuber harvesting using a 1-to- 5 severity rating scale, where $1=0$ to $5,2=>5$ to $10,3=>10$ to $25,4=>25$ to 50 , and $5=>50 \%$ of plant area affected.

${ }^{\text {h }}$ Susceptible male parent.

${ }^{\mathrm{i}}$ Resistant female parent. 
resistant parents, respectively, while $44.8 \%(n=43)$ of the progenies had severity similar to their resistant female parent (Table 4 ).

Spore production was lower in $93.8 \%(n=90)$ of the progenies than in the susceptible male parent, while $24.0 \%(n=23)$ of the progenies had spore production higher than in their resistant female parents. About $2 \%(n=2)$ and $41 \%(n=39)$ of the progenies had C. gloeosporioides spore production similar to that of their susceptible and resistant parents, respectively (Table 4).

About $96 \%(n=92)$ and 25\% $(n=24)$ of the progenies had anthracnose lesion size smaller than their susceptible male and resistant female parents, respectively, while $34.4 \%(n=33)$ of the progenies had bigger anthracnose lesions than those of their resistant female parent. About $41 \%(n=39)$ of the progenies had recorded anthracnose lesion sizes similar to that of the resistant female parent (Table 4).

Field evaluation of the F1 yam mapping population for anthracnose resistance and tuber yield. The field experiment, conducted to corroborate laboratory and greenhouse anthracnose screening parameters, had high disease pressure across the 2 years, and the susceptible male parent had a severity of 4.0. Disease severity in the resistant yam parent was moderate at 3.0 (Table 4). About $23 \%(n=22)$ and $70 \%(n=67)$ of the yam progenies had field severity lower than their resistant female and susceptible male parents, respectively. About $30 \%(n=29)$ and 2\% $(n=2)$ of the progenies had higher field anthracnose severity ratings than their resistant and susceptible parents, respectively, while $46.9 \%(n=45)$ of the yam progenies had field anthracnose severity scoring similar to that of their resistant female parent (Table 4).

There were significant $(P<0.001)$ differences in tuber yield for yam genotypes. Yam tuber yield was $1,667 \mathrm{~kg} / \mathrm{ha}$ for the anthracnosesusceptible male parent and 14,333 kg/ha for the anthracnose-resistant female parent. In all, 94 progenies had tuber yield higher than the susceptible parent and 57 progenies had tuber yield higher than their resistant parent. Two progenies had tuber yield similar to their anthracnoseresistant parent (Table 4).

About $2 \%$ of the progenies were classified as highly resistant, $20.8 \%$ as resistant, $46.9 \%$ as moderately resistant, $28.1 \%$ as susceptible, and $2.1 \%$ as highly susceptible for field anthracnose severity (Fig. 2E) but all five rating systems combined were only able to simultaneously capture $1.0,7.3,15.6,8.3$, and $1.0 \%$ of the progenies as highly resistant, resistant, moderately resistant, susceptible, and highly susceptible, respectively. For a yam genotype to be rated as highly resistant, resistant, moderately resistant, susceptible, or highly susceptible in graph $\mathrm{F}$ it had to be rated as highly resistant, resistant, moderately resistant, susceptible, or highly susceptible, respectively, in graphs A to E (Fig. 2F).

\section{Discussion}

The whole-plant anthracnose severity rating is widely used as the standard screening parameter for anthracnose resistance in yam, mostly in greenhouse settings as one-time scoring of final disease severity (Mignouna et al. 2001; Onyeka et al. 2006b) or cumulative

Table 4. (continued from preceding page)

\begin{tabular}{|c|c|c|c|c|c|c|}
\hline \multirow[b]{3}{*}{ F1 yam population ${ }^{b}$} & \multicolumn{4}{|c|}{ Laboratory and greenhouse anthracnose screening } & & \\
\hline & \multirow{2}{*}{ 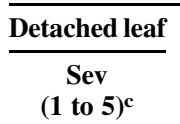 } & \multicolumn{3}{|c|}{ Whole plant } & \multicolumn{2}{|c|}{ Field evaluation } \\
\hline & & $\begin{array}{c}\text { Sev } \\
(1 \text { to } 5)^{d}\end{array}$ & $\begin{array}{l}\text { Lesion } \\
(\mathbf{m m})^{\mathrm{e}}\end{array}$ & $\begin{array}{c}\text { Spore production } \\
\left(\times 10^{3} \text { conidia } / \mathrm{cm}^{2} \text { leaf lesion }\right)^{\mathrm{f}}\end{array}$ & $\begin{array}{l}\text { Anthracnose } \\
(1 \text { to } 5)^{\mathrm{g}}\end{array}$ & $\begin{array}{c}\text { Tuber yield } \\
\text { (kg/ha) }\end{array}$ \\
\hline TDa 10/01023 & 2.0 & 1.0 & 1.8 & 0.4 & 2.0 & $28,333.0$ \\
\hline TDa 10/00939 & 2.0 & 2.0 & 1.7 & 2.2 & 2.0 & $25,667.0$ \\
\hline TDa 10/00941 & 2.0 & 2.0 & 3.4 & 1.1 & 2.0 & $21,333.0$ \\
\hline TDa 10/01129 & 2.0 & 2.0 & 2.0 & 1.7 & 3.0 & $23,000.0$ \\
\hline TDa 10/00989 & 3.0 & 3.0 & 9.7 & 2.7 & 3.0 & $25,333.0$ \\
\hline TDa 10/01000 & 2.0 & 3.0 & 3.1 & 3.4 & 3.0 & $14,333.0$ \\
\hline TDa $10 / 01136$ & 2.0 & 3.0 & 5.7 & 3.0 & 3.0 & $11,333.0$ \\
\hline TDa $10 / 00923$ & 3.0 & 3.0 & 5.1 & 4.5 & 3.0 & $7,333.0$ \\
\hline TDa $10 / 01033$ & 3.0 & 3.0 & 3.7 & 2.2 & 3.0 & $19,667.0$ \\
\hline TDa $10 / 01092$ & 3.0 & 3.0 & 3.7 & 3.4 & 3.0 & $6,000.0$ \\
\hline TDa 10/00962 & 2.0 & 2.0 & 1.4 & 1.5 & 3.0 & $17,000.0$ \\
\hline TDa 10/00906 & 3.0 & 3.0 & 6.0 & 3.7 & 3.0 & $14,333.0$ \\
\hline TDa 10/00918 & 3.0 & 3.0 & 4.0 & 3.5 & 3.0 & $12,667.0$ \\
\hline TDa 10/01012 & 4.0 & 4.0 & 4.8 & 5.1 & 4.0 & $15,333.0$ \\
\hline TDa 10/01067 & 3.0 & 4.0 & 5.0 & 5.0 & 4.0 & $8,333.0$ \\
\hline TDa 10/00963 & 3.0 & 4.0 & 6.0 & 5.4 & 4.0 & $16,333.0$ \\
\hline TDa 10/00973 & 4.0 & 4.0 & 11.6 & 7.8 & 4.0 & $9,667.0$ \\
\hline TDa 10/01056 & 4.0 & 4.0 & 7.4 & 5.9 & 4.0 & $16,333.0$ \\
\hline TDa $10 / 01125$ & 3.0 & 3.0 & 3.7 & 3.4 & 4.0 & $17,000.0$ \\
\hline TDa 10/01132 & 3.0 & 3.0 & 7.7 & 5.0 & 4.0 & $10,000.0$ \\
\hline TDa $10 / 01135$ & 4.0 & 4.0 & 5.7 & 6.4 & 4.0 & $10,333.0$ \\
\hline TDa $10 / 01134$ & 4.0 & 4.0 & 6.9 & 6.6 & 4.0 & $17,333.0$ \\
\hline TDa 10/01086 & 4.0 & 4.0 & 4.3 & 7.3 & 4.0 & $11,000.0$ \\
\hline TDa 10/01085 & 4.0 & 4.0 & 8.0 & 6.7 & 4.0 & $6,667.0$ \\
\hline TDa 10/01122 & 4.0 & 4.0 & 9.3 & 9.0 & 4.0 & $3,000.0$ \\
\hline TDa 10/01006 & 4.0 & 4.0 & 9.0 & 7.7 & 4.0 & $5,000.0$ \\
\hline TDa $10 / 00995$ & 4.0 & 4.0 & 6.9 & 7.2 & 4.0 & $4,667.0$ \\
\hline TDa $10 / 01032$ & 4.0 & 4.0 & 10.3 & 6.4 & 4.0 & $8,333.0$ \\
\hline TDa 10/01016 & 3.0 & 4.0 & 4.3 & 8.7 & 4.0 & $10,333.0$ \\
\hline TDa 10/00992 & 3.0 & 4.0 & 5.0 & 5.1 & 4.0 & $15,333.0$ \\
\hline TDa 10/01096 & 3.0 & 4.0 & 4.7 & 5.2 & 4.0 & $23,333.0$ \\
\hline TDa $10 / 00975$ & 4.0 & 4.0 & 7.7 & 7.0 & 5.0 & $10,667.0$ \\
\hline TDa 10/01070 & 5.0 & 5.0 & 20.7 & 12.9 & 5.0 & $1,330.0$ \\
\hline $\mathrm{LSD}_{0.05}$ & $\ldots$ & $\ldots$ & 3.1 & 0.8 & $\ldots$ & $1,397.0$ \\
\hline
\end{tabular}


scorings of disease severity (e.g., area under the disease progress curve) (Onyeka et al. 2006a; Sweetmore et al. 1994). The wholeplant anthracnose severity in the greenhouse and detached-leaf anthracnose severity in the laboratory offered the best reliability among the anthracnose rating parameters because they showed the highest positive agreement with field anthracnose severity, and had the least predicted residual means and best variance homogeneity. Although an early study had successfully evaluated the detached-leaf severity for anthracnose resistance response (Green et al. 2000), the parameter has not been commonly used to screen yam genotypes for anthracnose resistance. However, its effectiveness as a reliable screening parameter has been explored in other plant pathosystems (Newhouse et al. 2014).

Anthracnose lesion size rating had small predicted residual means but showed moderate positive agreement with field anthracnose severity and overall variance was heterogeneous, possibly due to unpredicted enlargement of lesions as a result of coalescence of a few or several lesions. Lesion size rating has widely been used to either screen crop genotypes for disease resistance (Metz et al. 2012; Nutter and Pederson 1985) or identify components of disease resistance (Berger et al. 1997; da Silva et al. 2012; Tredway et al. 2003).

The measurement of spore production, which indicates the ability of a pathogen to infect and reproduce, is highly accurate and less prone to the subjectivity of a rater (Johnson and Taylor 1976).
Nevertheless, spore counts are tedious, often time consuming, and have mostly been used to predict epidemics by collecting information on number and viability of spores landing in a field (for short- and long-distance movements). Apart from disease forecasting, spore production has also been used in plant disease resistance screenings in cucurbits for Oomycetes (Criswell et al. 2008), in monocots for Basidiomycetes (Priestley and Doling 1972; Torres and Browning 1968), and in dicots for Deuteromycetes (Foster et al. 1980; Rossi et al. 2000), among others. In this study, spore production as a rating parameter for anthracnose resistance screenings in yam showed moderate positive agreement with field anthracnose severity, had high predicted residual means and variance heterogeneity, and required data transformation before statistical analysis.

Young yam plants are highly prone to anthracnose and early infections by $C$. gloeosporioides may lead to severe disease and plant dieback. For a susceptible yam genotype, all growth stages are infected and late infections occurring in adult plants can also progress to severe disease and result in significant yield loss. For a resistant yam genotype, only younger leaf veins are infected and the small, developed anthracnose lesions do not expand in mature leaves. Thicker cuticle and cell walls and the development of leaf surface waxes in adult plants or plant tissues are some of plant defense mechanisms associated with adult plant resistance to plant pathogens. Adult plant resistance with Puccinia graminis in barberry and Taphrina deformans in
A

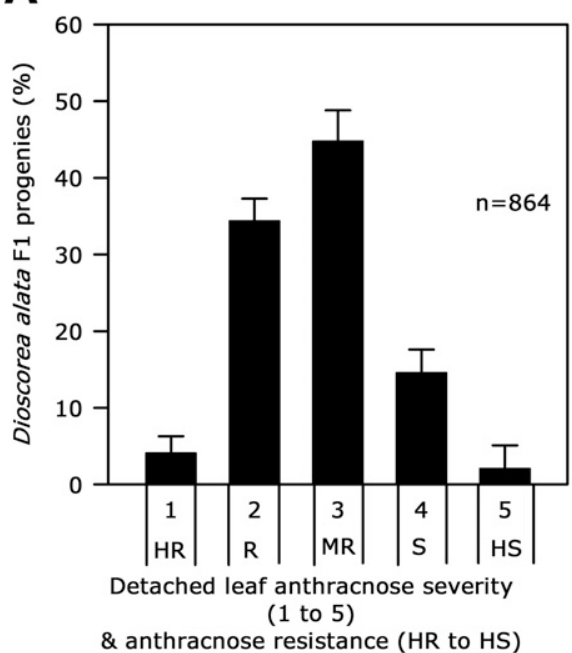

D

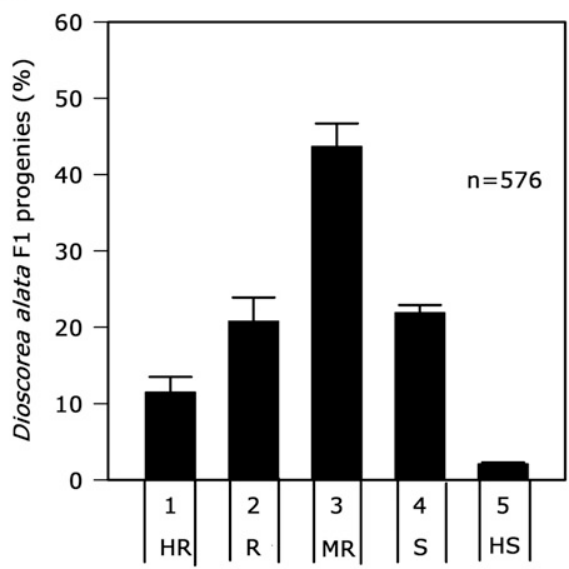

Whole-plant spore production (1 to 5 ) \& anthracnose resistance (HR to HS)
B

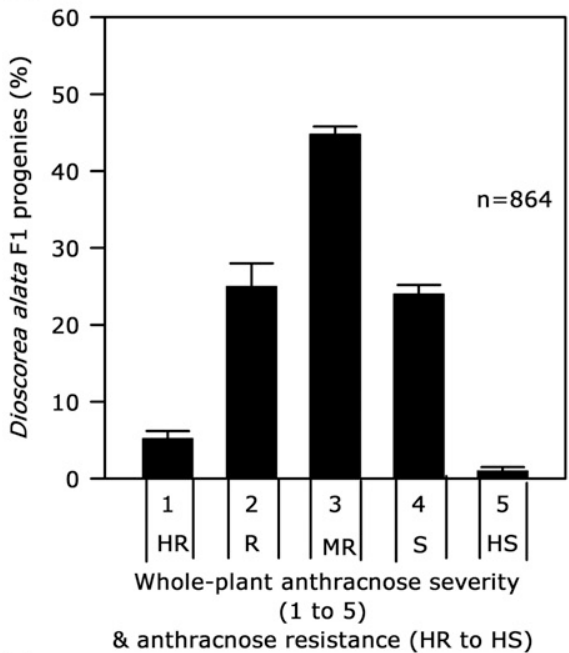

E

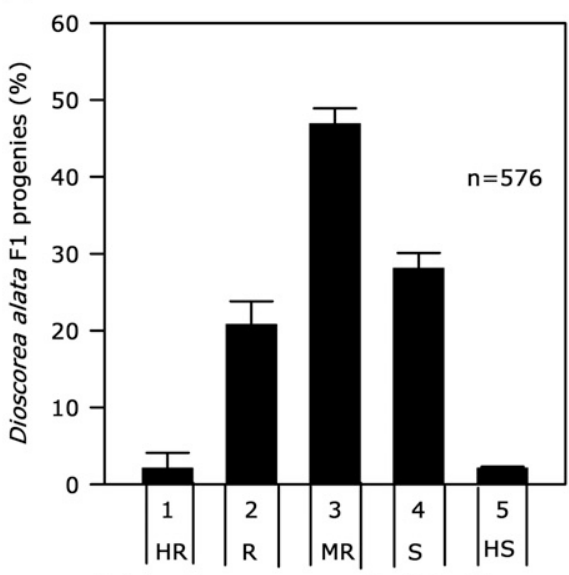

Field anthracnose severity ( 1 to 5 )

\& anthracnose resistance (HR to HS)

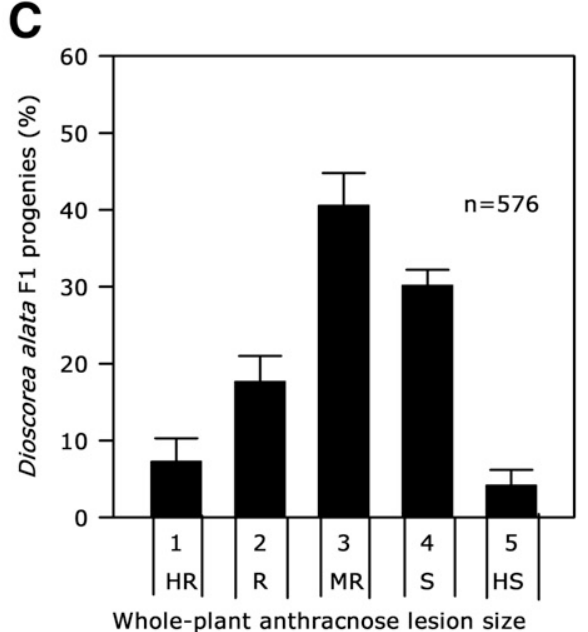

(1 to 5$)$

\& anthracnose resistance (HR to HS)
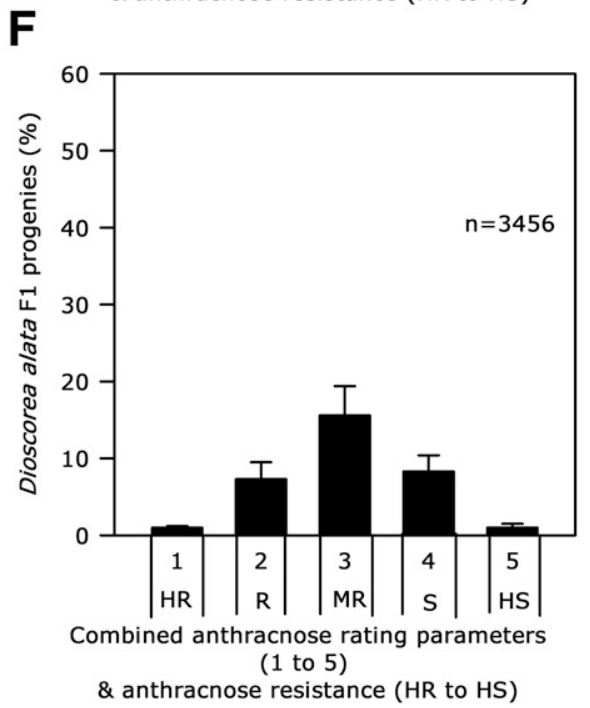

Fig. 2. Distribution of the F1 yam population using A, detached-leaf severity; B, whole-plant severity; C, lesion size; D, Colletotrichum gloeosporioides spore production; E, field anthracnose severity; and F, all combined as anthracnose rating parameters. Genotypes in the F1 yam population were classified as $1=$ highly resistant (HR), $2=$ resistant $(\mathrm{R}), 3=$ moderately resistant (MR), 4 = susceptible (S), and $5=$ highly susceptible (HS) following anthracnose ratings in the laboratory, greenhouse, and field. For a yam genotype to be rated as $H R, R, M R, S$, or $H S$ in graph $F$ it had to be rated as $H R, R, M R$, $S$, or HS, respectively, in graphs $A$ to $E$. 
peach has been attributed to the inability of these plant pathogens' germ tubes to penetrate thicker cuticles of the mature leaves (Guest and Brown 1997). In avocado, antifungal lipids dienes (Prusky et al. 1982) and the production of reactive oxygen species during infection (Beno-Moualem and Prusky 2000) in unripe fruit confer resistance against $C$. gloeosporioides, and only ripe fruit are successfully infected and develop anthracnose symptoms. For yam, adult plant resistance and possible mechanisms involved have not been explored but a locus Dcg-1 that confers resistance against $C$. gloeosporioides has been identified (Mignouna et al. 2002). Screenings for yam anthracnose resistance in controlled settings are usually carried out during early stages of plant growth while field anthracnose assessments are conducted in adult plants.

This study shows that detached-leaf severity in the laboratory and greenhouse whole-plant severity, lesion size, and spore production can effectively discriminate yam genotypes into distinct phenotypic groups of anthracnose resistance responses. The findings in this study provide the first comprehensive insights on comparative reliability and applicability of various anthracnose screening parameters in yam, for which results are in line with field anthracnose severity evaluations.

\section{Acknowledgments}

This research work was co-funded by the IITA; CGIAR Program on Roots, Tubers \& Banana (CRP-RTB); and the USAID-Linkage Grant.

\section{Literature Cited}

Abang, M. M., Green, K. R., Wanyera, N. W., and Iloba, C. 2001. Characterization of Colletotrichum gloeosporioides Penz. from yam (Dioscorea spp.) in Nigeria. Pages 613-615 in: Root Crops in the 21st Century: Proc. 7th Triennial Symp. Int. Soc. Trop. Root Crops-Africa Branch. M. O. Akoroda and J. M. Ngeve, eds. Cotonou, Benin.

Acha, I. A., Shiwachi, H., Asiedu, R., and Akoroda, M. O. 2004. Effect of auxins on root development in yam (Dioscorea rotundata) vine. Trop. Sci. 44:80-84.

Aduramigba-Modupe, A. O., Asiedu, R., and Odebode, A. C. 2008. Reaction of Dioscorea alata (water yam) to anthracnose disease in Nigeria. Food Agric. Environ. 6:248-252.

Agele, S. O., Ayankanmi, T. G., and Kikuno, H. 2010. Effects of synthetic hormone substitutes and genotypes on rooting and mini tuber production of vines cuttings obtained from white yam (Dioscorea rotundata, Poir). Afr. J. Biotechnol. 9:4714-4724.

Akem, C. N., and Asiedu, R. 1994. Distribution and severity of yam anthracnose in Nigeria. Pages 297-301 in: Root Crops for Food Security in Africa: Proc. Int. Soc. Trop. Root Crops (ISTRC)-Africa branch. M. O. Akoroda, ed. Kampala, Uganda.

Alderman, S. C., and Beute, M. K. 1987. Influence of temperature, lesion water potential, and cyclic wet-dry periods on sporulation of Cercospora arachidicola on peanut. Phytopathology 77:960-963.

Bayart, J. D., and Pallas, B. 1994. Tolerance of yam anthracnose to benzimidazoles: Results of the first study conducted in Guadeloupe. Phytoma 461:37-40.

Beno-Moualem, D., and Prusky, D. 2000. Early events during quiescent infection development by Colletotrichum gloeosporioides in unripe avocado fruits. Phytopathology 90:553-559.

Berger, R. D., Bergamin Filho, A., and Amorim, L. 1997. Lesion expansion as an epidemic component. Phytopathology 87:1005-1013.

Cohen, J. 1960. A coefficient of agreement for nominal scales. Educ. Psychol. Meas. 20:37-46.

Criswell, A. D., Wehner, T. C., Klosinska, U., and Kozik, E. 2008. Use of sporulation and other leaf and vine traits for evaluation of resistance to downy mildew in cucumber. Pages 433-440 in: Proc. IXth EUCARPIA Meet. Genet. Breed. Cucurbitaceae. M. Pitrat, ed. Avignon, France.

da Silva, M. R., Martinelli, J. A., Federizzi, L. C., Chaves, M. S., and Pacheco, M. T. 2012. Lesion size as a criterion for screening oat genotypes for resistance to leaf spot. Eur. J. Plant Pathol. 134:315-327.

Foster, D. J., Beute, M. K., and Wynne, J. C. 1980. Spore production and latent period as mechanisms of resistance to Cercospora arachidicola in four peanut genotypes. Peanut Sci. 7:88-90.

Gordon, S. G., Lipps, P. E., and Pratt, R. C. 2006. Heritability and components of resistance to Cercospora zeae-maydis derived from maize inbred VO613Y. Phytopathology 96:593-598.

Green, K. R., Abang, M. M., and Iloba, C. 2000. A rapid bioassay for screening yam germplasm for response to anthracnose. Trop. Sci. 40:132-138.

Guest, D., and Brown, J. 1997. Plant defences against pathogens. Pages 263-286 in: Plant Pathogens and Plant Diseases. J. F. Brown and H. J. Ogle, eds. Rockvale Publications, Armidale, NSW Australia.
Gumpert, F.-M. 1989. Measuring disease progress in pure and mixed stands of plant cultivars. Phytopathology 79:968-973.

Hepperly, P., and Vazquez, F. 1991. Resistance and scouting in the control of yam anthracnose of the winged yam (Dioscorea alata). Pages 587-596 in: Proc. 25th Annu. Meet. Caribbean Food Crops Soc. Gosier, Guadeloupe.

Johnson, R., and Taylor, A. J. 1976. Spore yield of pathogens in investigations of the race specificity of host resistance. Annu. Rev. Phytopathol. 14:97-119.

Kikuno, H., Matsumoto, R., Shiwachi, H., Youohara, H., and Asiedu, R. 2007. Comparative effects of explants sources and age of plant on rooting, shooting and tuber formation of vine cutting of yams. Jpn. J. Trop. Agric. 51:71-72.

Lin, L. I.-K. 1989. A concordance correlation coefficient to evaluate reproducibility Biometrics 45:255-268.

Metz, S. P., Chandra, A., Genovesi, A. D., and Campos, C. F. 2012. Comparison of screening methods to evaluate the response of St. Augustine grass to Magnaporthe oryzae. Plant Pathol. 61:255-261.

Mignouna, H. D., Abang, M. M., Green, K. R., and Asiedu, R. 2001. Inheritance of resistance in water yam (Dioscorea alata) to anthracnose (Colletotrichum gloeosporioides). Theor. Appl. Genet. 103:52-55.

Mignouna, H. D., Abang, M. M., Onasanya, A., and Asiedu, R. 2002. Identification and application of RAPD markers for anthracnose resistance in water yam (Dioscorea alata). Ann. Appl. Biol. 141:61-66.

Mignucci, J. S., Hepperly, P. R., Green, J., Torres-Lopez, R., and Figueroa, L. A. 1988. Yam protection II. Anthracnose, yield and profit of monocultures and interplantings. J. Agric. Univ. P. R. 72:179-189.

Newhouse, A. E., Spitzer, J. E., Maynard, C. A., and Powell, W. A. 2014. Chestnut leaf inoculation assay as a rapid predictor of blight susceptibility. Plant Dis. 98:4-9.

Nickerson, C. A. E. 1997. A Note on a concordance correlation coefficient to evaluate reproducibility. Biometrics 53:1503-1507.

Nutter, F. W., Jr., and Pederson, V. D. 1985. Receptivity, incubation period, and lesion size as criteria for screening barley genotypes for resistance Pyrenophora teres. Phytopathology 75:603-606.

Nwankiti, O. A., Okoli, O. O., and Okpala, E. O. 1987. Screening of water yam (Dioscorea alata) cultivars for tolerance to anthracnose/blotch disease. Fitopatol. Bras. 12:36-39.

Onyeka, T. J., Petro, D., Ano, G., Etienne, S., and Rubens, S. 2006a. Resistance in water yam (Dioscorea alata) cultivars in the French West Indies to anthracnose disease based on tissue culture derived whole plant assay. Plant Pathol. 55: 671-678.

Onyeka, T. J., Petro, D., Etienne, S., Jacqua, G., and Ano, G. 2006b. Optimizing controlled environment assessment of levels of resistance to yam anthracnose disease using tissue culture-derived whole plants. J. Phytopathol. 154:286-92.

Palaniyandi, S. A., Yang, S. H., Cheng, J. H., Meng, L., and Suh, J.-W. 2011. Biological control of anthracnose (Colletotrichum gloeosporioides) in yam by Streptomyces sp.MJM5763. J. Appl. Microbiol. 111:443-455.

Parlevliet, J. E. 1993. What is durable resistance? A general outline. Pages 23-39 in: Durability for Disease Resistance. J. T. Parlevliet, ed. Springer Netherlands, Dordrecht, The Netherlands.

Priestley, R. H., and Doling, D. A. 1972. A technique for measuring the spore production of yellow rust (Puccinia striifurmis) on wheat varieties. Pages 219-223 in: Proc. Eur. Mediterr. Cereal Rusts Conf. Prague, Czech Republic.

Prusky, D., Keen, N. T., Sims, J. J., and Midland, S. L. 1982. Possible involvement of an antifungal diene in the latency of Colletotrichum gloeosporioides on unripe avocado fruit. Phytopathology 72:1578-1582.

Reis, E. M., Casa, R. T., Blum, M. M. C., Santos, H. P., and Medeiros, C. A. 1997 Effects of cultural practices on the severity of leaf blotches of wheat and its relationship to the incidence of pathogenic fungi in the harvested seed. Fitopatol. Bras. 22:407-412.

Rossi, V., Battilani, P., Chiusa, G., Giosuè, S., Languasco, L., and Racca, P. 2000. Components of rate-reducing resistance to Cercospora leaf spot in sugar beet: conidiation length, spore yield. J. Plant Pathol. 82:125-131.

Ryo, M., Hironobu, S., Hidehiko, K., Kenji, I., Hidekazu, T., Atsushi, K., and Hiroshi, F. 2010. Characterization of sprouting and shoot formation process of rooted cuttings of water yam (D. alata). Trop. Agric. Dev. 54:107-112.

Simons, S. A., and Green, K. R. 1994. Epidemiology of yam anthracnose: Sources of inoculum. Pages 67-69 in: Proc. 4th Int. Conf. Plant Prot. Trop. Kuala Lumpur, Malaysia.

Sweetmore, A., Simons, S. A., and Kenward, M. 1994. Comparison of disease progress curves for yam anthracnose (Colletotrichum gloeosporioides). Plant Pathol. 43:206-215.

Torres, E., and Browning, J. A. 1968. The yield of uredospores per unit of sporulating area as a possible measure of tolerance of oats to crown rust. (Abstr.) Phytopathology 58:1070.

Tredway, L. P., Stevenson, K. L., and Burpee, L. L. 2003. Components of resistance to Magnaporthe grisea in 'Coyote' and 'Coronado' tall fescue. Plant Dis. 87:906-912.

Weir, B. S., Johnston, P. R., and Damm, U. 2012. The Colletotrichum gloeosporioides species complex. Stud. Mycol. 73:115-180.

Winch, J. E., Newhook, F. J., Jackson, G. V. H., and Cole, J. S. 1984. Studies of Colletotrichum gloeosporioides disease on yam (Dioscorea alata) in the Solomon Islands. Plant Pathol. 33:467-77. 